\title{
Willingness To Pay And Its Role In Health Economics
}

\author{
Syed Muslim Abbas, Ambreen Usmani, Maroosha Imran
}

ABSTRACT:

A stated preference which refers to the valuation of benefits in monetary terms to the health-related commodities or services are loosely termed as willingness to pay (WTP). Studies in health economics which are derived by surveys or experiments have been conducted addressing this issue. However, most economists have the view that stated preference or willingness to pay is an acceptable method if inclined with the aims of economic analysis. There has been a rapid growth of the health industry in the last few decades to meet the healthcare needs of an ever-growing population of the world with varying patterns of burden of disease and health related issues. This has escalated healthcare costs significantly putting pressure on governments to allocate additional finances in the health sector. In developing nations and some developed countries health services are mostly purchased privately as the governmental annual health budgets struggle to meet the healthcare demand of the communities.

Its relevance is increased in countries where people are expected to contribute significantly towards the costs of healthcare. Similarly, the strength of preference of health-related commodities is an important indicator for making prudent choices in deciding between competing health program which may be publicly funded. Moreover, other advantages of using WTP as outcome measure include; demand for information, process utility, option value and altruistic value. Demand for information encompasses the utility gained by individuals from the information included in the WTP survey. To conclude willingness to pay methodology is a useful tool in health economics to capture the preference of individuals who are the direct beneficiaries of the proposed health services.

\section{INTRODUCTION:}

'Willingness to Pay' (WTP) instruments as defined by Donaldson measure 'strength of preference' for, or value of, a commodity. In healthcare sector the conventional markets do not exist particularly in welfare states as either health services are provided free or heavily subsidized ${ }^{\mathbf{1 , 2}}$. Yet important decisions have to be made pertaining to allocation of scarce resources. Therefore, it is important to attribute valuation to resource costs for health interventions and its associated benefits. 'Hypothetical WTP questions in healthcare are utilized to elicit community values to choose combination of interventions which maximizes the value of benefits to the community ${ }^{\mathbf{3}, 4}$. A stated preference which refers to the valuation of benefits in monetary terms to the health-related commodities or services are loosely termed as WTP studies in health economics which are derived by surveys or experiments. The technique of measuring valuation is by offering people an opportunity to give direct values or

I Syed Muslim Abbas
Assistant Professor-Community Health Sciences
I Fatima Memorial Hospital Medical and Dental College
I Shadman, Lahore
I Ambreen Usmani
I HOD- Anatomy, DD-Medical Education
I Bice Principal Medical College
I E-mairia University Medical and Dental College, Karachi
| |
I Maroosha Imran
I Ziauddin University
I Karachi
I Received: 02-11-18
I Accepted: 11-12-18

providing them hypothetical market scenarios to document their responses ${ }^{\mathbf{5 , 6}}$. Morris explains that the theoretical basis of stated preference is psychological which is often disagreed by extreme views associated with Austrian economics which state that choices in real market have relevance to economic analysis. However, most economists have the view that stated preference or willingness to pay is acceptable method if inclined with the aims of economic analysis. Olsen explains that one of the greatest challenges for publicly financed health services is the setting of priorities among competing healthcare programs. He further comments that non- health benefits derived from healthcare beyond the benefit derived from health outcome are important to acknowledge in economic evaluations. To capture such non-health benefits derived from healthcare WTP becomes more appropriate than just a Quality Adjusted Life Year calculated in cost utility analysis ${ }^{7}$.

There has been an increased number of WTP studies conducted in healthcare in recent decades. The two methods that have been employed include contingent valuation method and discrete choice experiments. The relevance of WTP studies and cost benefit analysis (which incorporates WTP to measure monetary benefits) ${ }^{\mathbf{8 , 9 , 1 0}}$ is more in countries which greatly rely on private health services based on health financing by patients themselves. In countries like UK where health services are mostly provided free or significantly subsidized conducting these studies can be challenging ${ }^{\mathbf{1 1}}$. For example, it is unethical for researchers to imply future costs on services which are provided free at present. However, in developing nations and countries where patients bare most of the cost of health-related expenses WTP studies, particularly contingent valuation studies have been conducted. 
These studies have more relevance to the functioning of health systems within these regions. Some examples include; WTP study conducted to measure willingness to pay for social health insurance among informal sector workers in China, cross border insurance health insurance between Mexico and USA; quality healthcare and willingness to pay for health insurance retention in slums of Kolkata India. Moreover, Neumann states that WTP surveys facilitate researchers to broadly investigate the health and non-health benefits of predictive tests. Neumann elaborates that WTP literature in healthcare in last few decades has encompassed different disease areas, treatment modalities, and survey methods ${ }^{12,13,14}$.

However, there are potential weaknesses associated with WTP methods. The commonly discussed in literature include the relatively under sensitive responses generated in WTP and inflation of valuation of a specific intervention. The under sensitive responses generated in WTP refer to the scope effects and nesting effects which over sights the attributes of a single commodity. Kemp as cited by Cookson describes inflation of valuation of a specific intervention as 'WTP methods tend to inflate valuations of the specific intervention that respondents are asked about, relative to interventions that respondents are not asked about'. Furthermore there are other biases associated with generating responses in WTP which will be discussed in detail in the section weaknesses and limitation of WTP methodology in health economics ${ }^{15,16}$.

The essay will broadly cover the following themes in an attempt to critically assess the application of WTP methodology in health economics; 'WTP studies in healthcare: A Global Perspective', 'Advantages of WTP Methodology', 'Weaknesses and limitations of WTP', 'Methods of collecting WTP information in Healthcare' and 'Brief overview of the recent advances in WTP and Cost benefit analysis in Health Economics'.

\section{WTP studies in Healthcare: A Global Perspective:}

There has been a rapid growth of the health industry in last few decades to meet the healthcare needs of an ever-growing population of the world with varying patterns of burden of disease and health related issue ${ }^{17}$. This has escalated healthcare costs significantly putting pressure on governments to allocate additional finances in the health sector. In developing nations and some developed countries health services are mostly purchased privately as the governmental annual health budgets struggle to meet the healthcare demand of the communities. In such circumstances setting priorities among competing health programs is a daunting task. It is important to consider the non-health benefits derived from healthcare and valuing societal preferences in context to their willingness to pay. In such conditions WTP becomes more relevant than just considering a Quality Adjusted Life Year during decision making. As stated by Olsen 'from a consumer sovereignty perspective, WTP is superior to
QALYs in that no restrictions are imposed on which attributes of a health care programme people are allowed to value ${ }^{18,19}$. Moreover, public health interventions are aimed generally for achieving long term health outcomes. Planning and implementation of preventive health programs require valuation of both health and non-health related benefits of the proposed interventions. It can be argued that cost benefit analysis including WTP has the welfare economics theoretical basis to substantiate the economic evaluation for decision making in publicly funded healthcare. ${ }^{20}$ Cost benefit analysis utilizing WTP aims to capture allocative efficiency ensuring that sum of all health gains are distributed in an equitable fashion. WTP studies have been reported globally addressing issues such as; public sector healthcare programs, health financing schemes, measuring health state improvement, health insurance retention, cross border health insurance, implementing preventive public health interventions, social health insurance of informal sector workers, WTP to lessen waiting times for health procedures, WTP for child survival and health related safety strategies. As substantiated by the studies quoted above health systems where patients have to bare most of their health costs obtaining WTP information is beneficial in decision making process pertaining to healthcare service delivery. By obtaining WTP values health services can be offered at costs which are acceptable to the target populations to achieve improved health outcomes. The health insurance schemes based on WTP are a good example where individuals can be included in health coverage in accordance with the weight of their stated preferences. Countries like UK where health services are provided free of cost or greatly subsidized WTP studies may be difficult to conduct as the participants would find difficulty in relating to the hypothesized market scenarios present in the contingent valuation approach. Therefore, the information obtained by cost benefit analysis is of limited use and policy recommendations by health governing body such as National Institute for Health and Care ${ }^{21}$ Excellence greatly relies on QALYs calculated in cost utility analysis in decision making. It can be argued that careful consideration and inclusion of information obtained from WTP along with QALYs can substantiate the decision-making process. This may be achieved by incorporating both the non- health benefits of health outcomes associated with interventions and stated preferences of the consumers advocating broader benefits of healthcare.

\section{METHODOLOGY:}

Literature search of material was done by using PubMed.com, the keywords used were willingness AND to Pay AND Health Economics

\section{LITERATURE REVIEW:}

Methods of collecting WTP information in healthcare:

There are two general approaches by which WTP can be assessed, namely, indirect and direct method. In indirect 
approach takes into consideration previous real life examples of trade offs between monetary values and associated health outcomes. On the contrary, the direct approach involves conducting surveys by providing hypothetical market scenarios to generate stated preferences or WTP ${ }^{1,218,22}$. This technique as previously discussed is termed as contingent valuation approach and is often implied in cost benefit analysis pertaining to healthcare. There are four ways discussed in literature how researchers may question respondents to register their WTP. Open-ended or continuous response question provides opportunity to respondents to state whatever value they want. This technique is simple but far stretched from real life market where consumers don't have the liberty to state a price of a good and receive it. Discrete choice or binary choice respondents are given a single value which they can accept or reject. Different values are presented randomly to different individuals in a sample to generated WTP values based on average responses from the entire sample. Payment scale involves providing respondents with a range of choices and iterative bidding allows the flexibility of raising and lowering an initial value by the respondent till the point they are unable to decide ${ }^{\mathbf{8 , 1 4 2 2 3}}$.

\section{Advantages of WTP Methodology:}

A salient feature of WTP methodology for economic evaluation is that it is supported by a theoretical foundation in welfare economics. As highlighted by Birch (2003) 'methods used to measure QALY share their theoretical roots with welfarist valuation method such as willingness to pay'. WTP captures wider benefits of health which include the non-health benefits of associated health outcomes and acknowledges people preferences during the decision-making process. Its relevance is increased in countries where people are expected to contribute significantly towards the costs of healthcare ${ }^{22,23}$. Similarly, the strength of preference of healthrelated commodities is an important indicator for making prudent choices in deciding between competing health program which may be publicly funded. Moreover, other advantages of using WTP as outcome measure include; demand for information, process utility, option value and altruistic value ${ }^{23}$. Demand for information encompasses the utility gained by individuals from the information included in the WTP survey. Whether it may be a hypothetical scenario presented in a contingent valuation approach or attributes of two different health services or commodities the information provided facilitates individuals in making informed decisions. Therefore, utility is gained by having access to relevant information pertaining to the health services. Process utility includes the advantage of utilizing value in health care or the process of care received by using WTP as an outcome measure. Option value refers to the utility gained by individuals pertaining to the increased awareness of the health care proposed in the survey or experiment of WTP study. Furthermore, WTP can serve as a tool to measure how individuals value others welfare which is referred to as the altruistic value. The applied examples of these advantages are explained in detail in the previous section labelled, 'WTP studies in healthcare, a global perspective ${ }^{24}$.

\section{Disadvantages and limitations of WTP methodology:}

There can be potential bias in the information that is measured in WTP studies. For instance, in contingent valuation studies where participants are provided with hypothetical market scenarios may highlight the issue of the artificial nature of choices that respondents register ${ }^{24}$. In real life settings the consumers make choices that may be influenced by the environment in which they make the choice in context to the dynamics of the real life market conditions ${ }^{23}$. On the contrary, in an experiment or survey the participants may derive utility from interaction with the researchers rather than the providers. This may lead to strategic responses even from the most rational consumers depending on the scenario that is presented in the survey leading to under or over statement of the WTP ${ }^{4,6,8}$. It is more likely that the respondents may report a low WTP for an intervention based in the future and over state on a subsidized or free health intervention or service. Another important issue of generating validated responses from respondents may arise when they are unable to share researchers aim. The understanding of the health service and experience of previous utilization is important for respondents for reporting accurate WTP values. If they don't have a proper understanding of the service, its significance or previous experience of using it they may resort to face saving strategy by giving responses which are far from their actual stated preference. There are challenges associated with making market scenarios realistic ${ }^{25}$. Moreover, the process of giving WTP responses may also be cognitively demanding. Other issues that may arise in generating WTP values include protest bids in which respondents provide inaccurate responses expressing their disapproval of the present health governing systems or health policies rather than taking into consideration the proposed health service on its own. Responses provided by such subjects may invalidate the WTP response. Furthermore, respondents may also state no amount of WTP resulting in zero bids. Errors in the stated WTP by individuals when extrapolated can yield large errors in population $\mathrm{WTP}^{25}$. There is a potential risk of these inflated and sometimes referred as 'rubber money' valuations can be exploited by pressure groups and stakeholders with vested interests to deviate efforts to achieve rational decision making. The potential biases in collecting WTP values highlighted above raises questions on the authenticity of the information generated by this methodology in health economics and its reliability in aiding the decisionmaking process ${ }^{4,5,16}$.

\section{Brief overview of recent advances in Cost Benefit Analysis and WTP technique in Health Economics:}

Despite the widespread use of incremental cost effectiveness 
ratios in making important policy recommendations particularly in developed nations the absence of economic theoretical basis in the extra welfarist approach and the exclusion of non-health benefits by such methodologies is well debated in literature ${ }^{17,18,19}$. There has been a rapid growth in the health sector with populations expected to pay for consuming health services in most of the countries. Therefore, in present times the assessment of cost benefit element of health services or interventions is very important specifically from a global health perspective. All economic evaluations have some element of 'cost-benefit' in them ${ }^{26,27,28}$. Cost benefit analysis (CBA) aims to capture all the associated costs and benefits of a health intervention comprehensively in monetary value. As stated by Mclntosh 'Recent methodological developments in monetary valuation for use in CBA are the development of the technique of willingness to pay, the use of conjoint analysis (CA) to elicit willingnessto-pay ${ }^{29,30,31}$ (WTP) values and advances in the debate on the inclusion of production gains in CBAs'. Furthermore, the balance sheet approach which is a form of cost benefit analysis emphasizes on the fact that benefits which cannot be quantified should not be ignored can be incorporated in ${ }^{32}$ CBA in circumstances even monetary valuation is not possible. There has been a re-emergence of significance of CBA in context to increasing private health systems globally but its wider application in making policy recommendations remains debatable ${ }^{33,34}$.

\section{CONCLUSION:}

To conclude willingness to pay methodology is a useful tool in health economics to capture the preference of individuals who are the direct beneficiaries of the proposed health services. The monetary valuation of health benefits is of significant relevance in health systems where people have to contribute mostly towards the health costs incurred. Health insurance and financing schemes can be based on the WTP which can help include communities into wider health coverage. Preventive interventions can also be planned and prioritized by utilizing WTP to target high risk groups and choose between competing health programs. From a developed country's perspective where health services are provided free or heavily subsidized WTP can be considered along with incremental cost effectiveness ratios calculated in cost utility and cost effectiveness analysis. Similarly, a study reported to estimated WTP for one additional QALY gained to determine the threshold of the incremental costeffectiveness ratio. However, there are potential weaknesses and bias in capturing WTP from respondents which can lead to false depiction of population willingness to pay once values are extrapolated. It is important to include all perspectives and aspects to make the most rational decisions pertaining to managing health resources. Health economics is an evolving field. The way forward would be an amalgam of the various techniques with careful consideration of associated strengths and weaknesses.

\section{REFERENCES:}

1. Arana JE, León CJ. Willingness to pay for health risk reduction in the context of altruism. Health Econ, 2002;11(7):623-635.

2. Anderson G, Black C, Dunn E, Alonso J, Christiana-Norregard J, Folmer-Anderson T, Bernth-Peterson P. Willingness to pay to shorten waiting time for cataract surgery. Health Affairs. 1997;16(5):181-190.

3. Birch S, Donaldson C. Valuing the benefits and costs of health care programmes: where's the 'extra' in extra-welfarism? Social science \& medicine. 2003;56(5):1121-33.

4. Bärnighausen T, Liu Y, Zhang X, Sauerborn R. Willingness to pay for social health insurance among informal sector workers in Wuhan, China: a contingent valuation study. BMC Health Services Research. 2007;7(1):114.

5. Bustamante AV, Ojeda G, Castañeda X. Willingness to pay for cross-border health insurance between the United States and Mexico. Health Affairs. 2008;27(1):169-178.

6. Blumenschein K, Johannesson M. Use of contingent valuation to place a monetary value on pharmacy services: an overview and review of the literature. Clin Ther. 1999;21(8):1402-17.

7. Donaldson C. and Shackley P. Does "process utility" exist? A case study of willingness to pay for laparoscopic cholecystectomy. Social Science \& Medicine,1994;44(5), 699-707.

8. Donaldson C. Valuing the benefits of publicly provided health care: does 'ability to pay' preclude the use of 'willingness to pay'? Social Science \& Medicine1999; 49:551-563.

9. Donaldson C, Shackley P. Willingness to pay for health care. Advances in health economics. 2003; 1-24

10. Fonta WM, Ichoku HE, Kabubo-Mariara J. The effect of protest zeros on estimates of willingness to pay in healthcare contingent valuation analysis. Applied health economics and health policy. 2010; 8(4):225-237.

11. Gustafsson-Wright E, Asfaw A, Van der Gaag J. Willingness to pay for Health Insurance; An Analysis of the Potential Market for Low-cost Health Insurance Products in Namibia. Social Science \& Medicine. 2009;69(9):1351-59.

12. Kemp MA, Maxwell C, 1993. Exploring a budget context for contingent valuation estimates. In Contingent Valuation: A Critical Assessment, Chapter 5. Hausman, JA (ed.) Cambridge Economics Inc: Cambridge MA, pp-217-265.

13. Lachaine J. Therapeutic options for the prevention and treatment of postoperative nausea and vomiting: a pharmacoeconomic review. Pharmacoeconomics, 2006;24(10):955-970.

14. Liu JT, Tsou MW, Hammitt JK. Willingness to pay for weightcontrol treatment. Health Policy. 2009;91(2):211-218.

15. Mathiyazaghan K. Willingness to pay for rural health insurance through community participation in India. The International journal of health planning and management. 1998; 13(1):4767.

16. McIntosh E, Donaldson C, Ryan M. Recent advances in the methods of cost-benefit analysis in healthcare. Pharmacoeconomics. 1999;15(4):357-367.

17. Morris S, Devlin N, Parkin D. Measuring and valuing health care output. In: Morris, S eds. Economic Analysis in Health Care. Second Edition, Chichester: Wiley, 2012; 256

18. Morris S, Devlin N, Parkin D. Measuring and valuing health care output. In: Morris, S eds. Economic Analysis in Health 
Care. Second Edition, Chichester: Wiley, 2012; 258

19. Morris S, Devlin N, Parkin D. Measuring and valuing health care output. In: Morris, S eds. Economic Analysis in Health Care. Second Edition, Chichester: Wiley, 2012;255-258

20. Nayak S, Roberts MS, Greenspan SL. Osteoporosis screening preferences of older adults. Journal of Clinical Densitometry, 2009;12(3):279-286

21. Neumann PJ, Cohen JT, Hammitt JK, Concannon TW, Auerbach HR, Fang C, Kent DM. Willingness-to-pay for predictive tests with no immediate treatment implications: a survey of US residents. Health econ. 2012;21(3):238-251

22. Noor AA, Aljunid SM. Systematic review of factors associated with willingness to pay for health financing scheme. Malaysian J Public Heal Med. 2017;17(2), pp.103-112

23. O'Brien B, Viramontes JL. Willingness to pay: a valid and reliable measure of health state preference? Medical Decision Making. 1994;14(3):289-297

24. Olsen JA, Smith RD. Theory versus practice: a review of 'willingness-to-pay' in health and health care. Health Econ. 2001;10(1):39-52.

25. Olsen JA, Donaldson C. Helicopters, hearts and hips: using willingness to pay to set priorities for public sector health care programmes. Social Science \& Medicine, 1998;46(1):112

26. Richardson J, Lezzi A, Sinha K, Khan MA, Mckie J. An instrument for measuring the social willingness to pay for health state improvement. Health econ. 2014;23(7):792-805.
27. Rodriguez-Monguio R, Otero MJ, Rovira J. Assessing the economic impact of adverse drug effects. Pharmacoeconomics. 2003; 21(9):623-650.

28. Sach TH, Smith RD, Whynes DK. A 'league table' of contingent valuation results for pharmaceutical interventions: a hard pill to swallow? Pharmacoeconomics., 2007; 25(2):107-127.

29. Shiroiwa T, Sung YK, Fukuda T, Lang HC, Bae SC, Tsutani $\mathrm{K}$. International survey on willingness-to-pay (WTP) for one additional QALY gained: what is the threshold of cost effectiveness? Health econ. 2010;19(4):422-437.

30. Thompson MS, Read JL, Liang M. Feasibility of willingnessto-pay measurement in chronic arthritis. Medical Decision Making. 1984;4(2):195-215.

31. Thompson MS. Willingness to pay and accept risks to cure chronic disease. American Journal of Public Health. 1986;76(4):392-396.

32. Watson V, Ryan M, Watson E. Valuing experience factors in the provision of Chlamydia screening: an application to women attending the family planning clinic. Value in Health. 2009;12(4):621-623.

33. Weaver M, Ndamobissi R, Kornfield R, Blewane C, Sathe A, Chapko M, Bendje N, Nguembi E, Senwara-Defiobonna J. Willingness to pay for child survival: results of a national survey in Central African Republic. Social Science \& Medicine. 1996;43(6):985-998.

34. Wagstaff A. QALYs and the equity-efficiency trade-off. Journal of health economics. 1991;10(1):21-41. 